\title{
Time weighted average concentration monitoringbased on thin film solid phase microextraction
}

FardinAhmadi $^{a}$, ChrisSparham $^{\mathrm{b}}$, EzelBoyacl $^{\mathrm{a}}$,JanuszPawliszyn $^{\mathrm{a} *}$

a Department of Chemistry, University of Waterloo, 200 University Avenue West, Waterloo, Ontario, N2L

3G1, Canada.

${ }^{b}$ Unilever, Safety \& Environmental Assurance Centre, Colworth Science Park, Sharnbrook, Bedford, MK44

$1 L Q, U K$. 
ABSTRACT: Time weighted average (TWA) passive sampling with thin film solid phase microextraction(TF-SPME) and liquid chromatography tandem mass spectrometry(LC-MS/MS) was used forcollection, identification, and quantification of benzophenone-1, benzophenone-2, benzophenone-3, benzophenone-4, 2-phenylbenzimidazole-5-sulfonic acid, octocrylene, octylmethoxycinnamate, butylmethoxydibenzoylmethane, triclocarban and triclosan in the aquatic environment. Two types of TF-SPME passive samplers, including a retracted thin film device using a hydrophilic lipophilic balance(HLB)coating, andan open bed configuration with anoctadecyl silica-based (C18)coating, were evaluated in anaqueous standard generation system.Laboratory calibration results indicated that the thin filmretracted device using HLB coatingis suitable to determine TWA concentrations of polar analytes in water, with an uptakethat waslinear up to 70 days. In open bed form, a one-calibrant kinetic calibration technique was accomplished by loading benzophenone $3-d_{5}$ as calibrant on the $\mathrm{C} 18$ coating to quantify allnon-polar compounds. The experimental results showed that the one-calibrant kinetic calibration technique can be used for determination of classes of compounds in cases wheredeuterated counterparts are either not available or expensive. The developed passive samplers were deployed in wastewater-dominated reaches of the Grand River (Kitchener, ON) to verify their feasibility for determinationof TWAconcentrationsinon-site applications. Field trials results indicated that these devices are suitable for long-term and short-term monitoring of compounds varying in polarity, such as UV blockers and biocide compounds in water, and the data were in good agreement with literature data. 
TOC/Abstract art

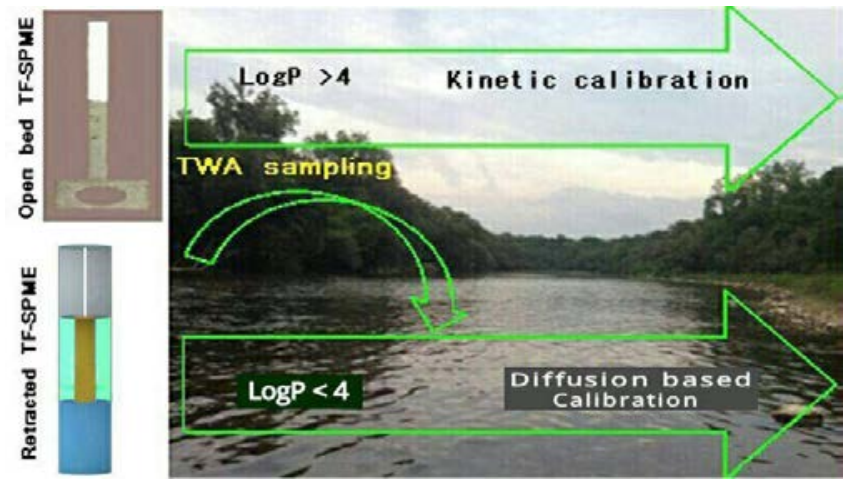




\section{INTRODUCTION}

The environmental impact of biocides and UV blockers hasreceivedincreasedattention within the past few years, as these ingredients can be found in various products used in everyday life, such as personal care products (PCPs), cleaning agents, paints, and coatings. ${ }^{1-2}$ They are used in large quantities on a daily basis, and are continuously discharged into surface water through municipal wastewater treatment planteffluent. In view of this, constant monitoring of concentrations of UV filters and biocides in aquatic environments is required for assessing water quality, whereby sampling is a crucial firststepthat can be achieved either through grab/spot sampling or passive sampling methods. However, the spot sampling method can only provide information regarding the system at the time and point of sampling.Consequently, spot sampling may not provide a realistic picture ofaquatic-life continuous exposure to biocides and UV blockers for prolonged periods of time. ${ }^{3}$ Traditionally, when levels of contaminants fluctuate within a body of water, collection of large numbersof samples over a prolongedperiod of time is needed to obtain a time weighted average (TWA) water concentration, a process thatis time consuming, laborious, and costly. ${ }^{4-5}$ TWA concentrations can be obtained in one of two ways: the first method includes the collection ofcomposite samples through employment of active sampling techniques, which can be accomplished, for example, by use of automatic or manual water samplers. Passive sampling methods, as an alternative option to the process described 
above, are now widely used for monitoring of TWA concentrations of environmental contaminants. $^{6,7}$

The passive sampling approach is based on the free movement of analytes from sample matrix to the extraction phase. Differences in the chemical potential of the analytes between two media cause accumulation of theanalytesinto the extraction phase. ${ }^{3-8}$ Passive sampling eliminatespower requirements, reduces analysis cost, and also prevents decomposition of the analyte during storage and transportation. ${ }^{9}$ Several passive sampling methods are used for monitoring of organic contaminants in water, including semi-permeable membrane devices (SPMDs), ${ }^{10,11}$ polar organic chemical integrative samplers (POCIS), ${ }^{12,13}$ Chemcatcher, ${ }^{4,14}$ ceramic dosimeters, ${ }^{7,15}$ low density polyethylene (LDPE), ${ }^{16-19}$ polymeric samplers, ${ }^{17,20}$ and membrane enclosed sorptive coatings. ${ }^{21}$ Passive sampling has gained popularity and a recently published articlehas proposed to establish a global network for monitoring organic contaminants in open waters, building upon the recent success of passive sampling techniques. ${ }^{22}$

Solid phase microextraction (SPME) was developed as a solvent-freesample preparationtechnique that integrates sampling, extraction, and pre-concentration in a single step. ${ }^{23}$ Owing to theseadvantages, it has been widely used for on-site sampling of a broad range of target analytes in different matrices. ${ }^{24-25} \mathrm{~A}$ SPME retracted device, in which the SPME fiber is retracted a certain distance into the needle housing during the sampling, has been used for TWA sampling in air ${ }^{26-27}$ and water ${ }^{28-29}$ for volatile and semi volatile compounds. However, this sampler technique is associated with some limitations,such as the loss of hydrophobic compounds on the diffusion path. ${ }^{30}$ Additionally, the low surface-to-volume ratio of the SPME 
fiber maypose constraints on sampling timeand the overall sensitivityof the method. ${ }^{31}$ Moreover, the chemistry of the coatingis mostlylimited to PDMS, which is not an appropriatecoating for hydrophilic analytes, and does not act as a zerosink for volatile compounds. ${ }^{26,}{ }^{30}$ Thin film solid phase microextraction (TF-SPME), a technique which provides ahighsurfacearea-to-volume ratio, has been introduced to overcome the low-capacity limitations and low extraction rates of traditional SPME fibers. ${ }^{32-33}$ The performance reference compounds (PRC)technique was first introduced by Booijet al. and Huckinset al. for calibration of uptake kinetics of semipermeable membrane devices. ${ }^{34,35}$ Thistechniquehas since then been adapted toapplications of TF-SPME for TWA sampling of polycyclic aromatic hydrocarbons (PAHs) in water, namely the kinetic calibration technique. ${ }^{28,36}$ However, there are factors that limit the application of traditional kinetic calibration for multiple compound analysis, sincepreloading of a number of calibrants is a complex process, and isotopically labelled counterparts may not always be available or affordable for all target analytes. To address these limitations, Ouyang et al. introduced the one-calibrant kinetic calibration technique, where one isotopically labelled standard was used in order to quantify multiple analytes of interest. ${ }^{37}$ In this study, wepropose two types of TF-SPME passive samplers: aretracted TF-SPME device and an open bed configuration TF-SPME device. Theproposed passive samplersoffer an integrated approach to TWA determination of analytes covering a wide range of physicalchemical properties for on-site applications. The herein presented methods were investigated in a flow-through aqueous standard generation system, which provides accurate calibration data of the devices over a wide polarity range of PCP chemicals.Employment of the aqueous 
standard generator systemallowed for the provision of an environmentally realistic calibration of hydrophobic compounds withoutincurring depletion of analytes. The samplerswere thendeployedin the Grand River (ON, Canada) to validate the suitability of the developed devices for on-site applications.

\section{MATERIALS ANDMETHODS}

Chemicals and Materials. The physical-chemical properties of eight UV blockers and two biocides compounds used in this study, namely octylmethoxycinnamate (OMC), benzophenone1 (Ben-1), benzophenone-2 (Ben-2), benzophenone-3 (Ben-3), benzophenone-4 (Ben-4), 2phenylbenzimidazole-5-sulphonic acid (PBSA), octocrylene (OCR), butylmethoxydibenzoylmethane (BM-DBM), triclosan (TCS), and triclocarban (TCC), are shown in Table S1 (Supporting Information).For details regarding the chemicals, materials, and stock solutions used in this study, see Supporting Information.

Instrumentation. For details related to use of LC-MS equipment, including methodology and mass spectrometric parameters used in the quantification of analytes, see Supporting Information and Table S2. 
Aqueous standards generation system. An aqueous standard generation system was used for development and evaluation of the TWA samplers, as it provides large volumes and a steady state concentration of analytes in water. For details related to theaqueousstandard generation systemused in this research, see Supporting Information.

SPME procedure using TF-SPME. The coating was immobilized on the blade with spraying methoddescribed by Mirnaghi et al. in which polyacrylonitrile (PAN) dissolved in N, Ndimethylformamide (DMF) is used as a glue for the immobilisation of functional particles to the blade. ${ }^{33}$ The thickness of thecoating on the blade was $200 \pm 10 \mu \mathrm{m}$. Retractedand open bed configurations of TF-SPME used in the studyareshown in Figure $1 \mathrm{a}$ and Figure $1 \mathrm{~b}$, respectively.For details related to TF-SPME method development, experimental procedures, preparation of field samplers, and related on-site sampling procedures, see Supporting Information. 
Retracted thin film solid phase microextraction. The design of the retracted TF-SPME TWA sampler is illustrated in Figure1a. The sampler consisted of a copper tube, caps, a Teflon rod assembly, a Teflon spacer (all made at the Machine Shop at the University of Waterloo), and a thin film (HLB particles) coated blade made in the laboratory. The copper tube was made from a copper rod that was drilled, creating a hole with a $0.76 \mathrm{~mm}$ inner diameter and $10.0 \mathrm{~mm}$ length (diffusion path). To avoid the trapping of air bubbles in the sampler, all parts of the sampler were assembled under ultrapure water. Assembly of the sampler was conducted by first locating the Teflon spacer inside the copper tube, followed by insertion of the thin film on the Teflon holder inside the copper tube, and finally, tightly screwing the cap to fix the TF-SPME in place. The sampler was then removed from the ultrapure water basin and transferred to the sampling chamber. In order to perform TWA sampling with retracted TF-SPME, three basic prerequisites have to be met. ${ }^{31,38}$ First, the coating of the TWA sampling device should act as a zero sink (also known as infinite sink) for all of the analytes under study, and the mass uptake rate should not be influenced by the amount of analytealready sorbed. The zero sink behavior of the coating was validated by a simple test whereby the TF-SPME devices were exposed to the aqueous standard generation in two separate modes: continuous and intermittent exposure. For continuous exposure, the selected analytes were extracted for 180 min from the aqueous standard generator before being exposed to pure water for $60 \mathrm{~min}$. As for intermittent exposure, 60 min of extraction from the aqueous standard generator was followed by exposure of the TF-SPME device into pure water for $60 \mathrm{~min}$. The intermittent exposure process was repeated three times and results of both exposure modes were compared. The difference 
between extracted amounts from both exposure modes was negligible, therefor proving the zero sink nature of the coating ${ }^{26}$. The second requirement is that the passive sampler should respond proportionally to changes in analyte concentrations at the face of the device. The capability of the device to integrate high peak concentrations is an important function of any passive sampler. ${ }^{31}$ The third condition is that the bulk concentration $\left(\mathrm{C}_{\text {bulk }}\right)$ of analytes must be equal to the concentration of analytes at the face of the device $\left(C_{\text {bulk }}=C_{\text {face }}\right)$. The overall masstransfer resistance of the analyte from the bulk of the samples to the collecting medium should be limited to the diffusion path of the sampler.
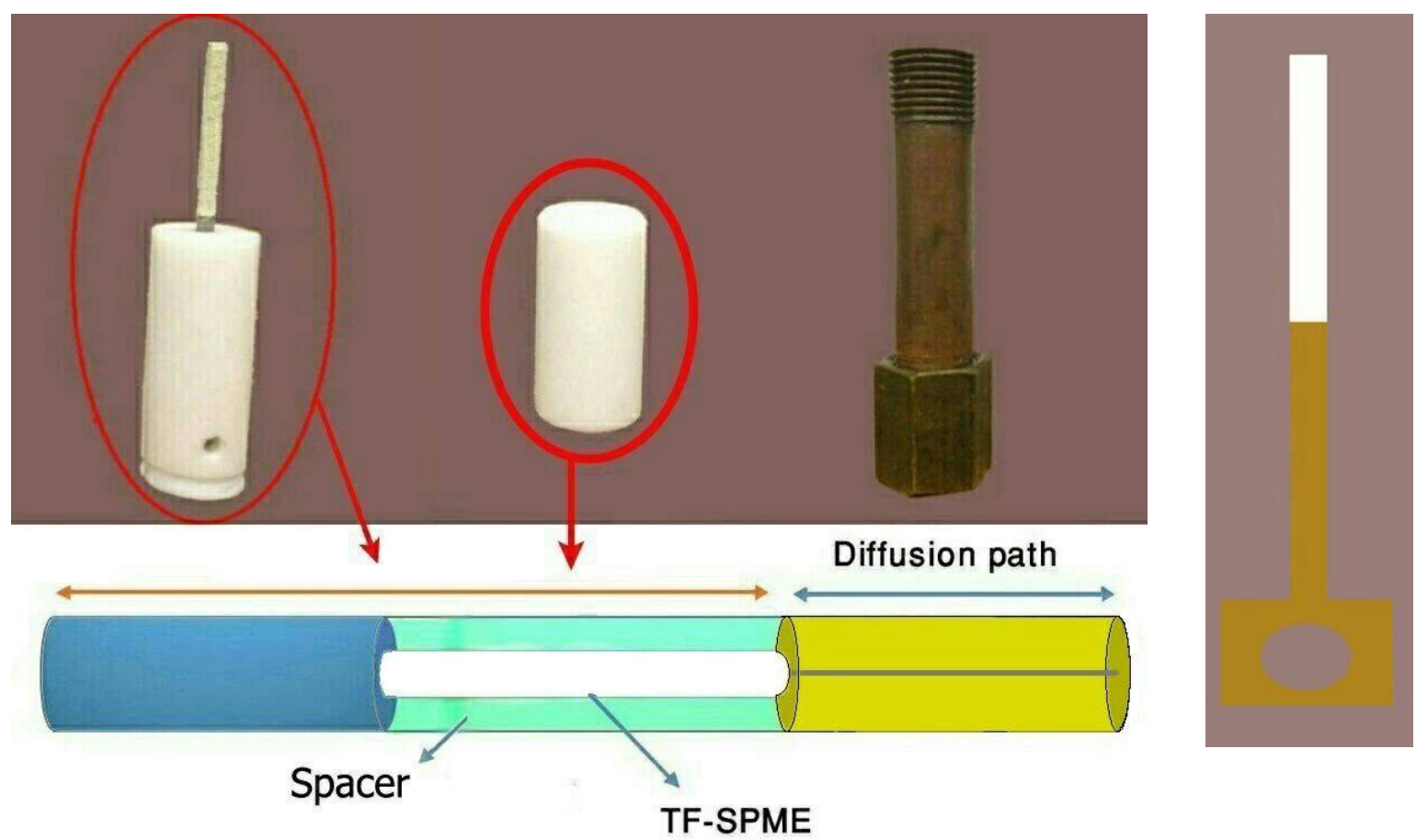

TF-SPME

(a)

(b) 
Figure 1. (a) Retracted TF-SPME TWA sampler (top figure from left to right: Teflon rod assembly with TF-SPME, Teflon spacer, copper tube with adrilled hole as diffusion path; bottom figure: schematic of assembled sampler), and (b) Open bed TF-SPME.

\section{Diffusion calibration of retracted TF-SPME sampler.Laboratory calibration of the}

TWA sampler was performed by placing nine samplers in the aqueous standard generator system simultaneously for different time intervals. The samplers were retrieved on the $30^{\text {th }}$, $56^{\text {th }}$ and $70^{\text {th }}$ day.Since the diffusion of analytes in stagnant water between the thin film and the opening of the sampler is controlled by the mass-transfer, the diffusion is assumed to follow Fick's first law under a steady state condition; as such, the mass uptake can be calibrated by use of Fick's first law of diffusion (equation 1).

$C=\frac{n Z}{A D t}$

Where $\mathrm{C}$ is the TWA concentration, $\mathrm{n}$ is the amount of analyte extracted, $\mathrm{Z}$ is the diffusion path length, $A$ is the cross-sectional area of the opening, $D$ is the diffusion coefficient, and $t$ is sampling time.

The diffusion coefficient of neutral and charged organic molecules in water can be obtained using equations S2 and S3 (see Supporting Information). For analytes which are predominantly presented in their ionic forms (e.g. Ben-4, PBSA) the diffusion coefficients were calculated based on equation S3. Whereas, if they are presented at equilibrium of neutral and ionic forms (e.g. Ben-1, Ben-2) equation S2 and S3 were used separately for neutral and ionic species, respectively, and then the average diffusion coefficients were determined.The ratio of theoretical sampling rate $\left(R_{s}\right)$ to analyte diffusion coefficient $(D)$ depends on the geometric 
configuration of the sampler only, i.e. $\left(R_{s} / D\right)=A / Z$. The ratio of theoretical sampling rate to the experimental sampling rate ( $R_{s}$ ) should be equal to 1 , which verifies that the sampler can be calibrated by diffusion-based calibration. For this purpose, samplers with three different diffusion paths were exposed in the sampling chamber with known concentrations of analytes for a defined time. By utilizing the amount of extracted analyteas determined by LC-MS/MS, the sampling rate could then be calculated with the following equation:

$S R=\frac{n}{C t} R_{S}=\frac{n}{C t}$

The device was calibrated at $24 \pm 1{ }^{\circ} \mathrm{C}$, and the water temperature in the sampling site varied from $19-22{ }^{\circ} \mathrm{C}$ during the sampling.The effect of temperature on the sampling rate was within the predetermined experimental error limits in this experiment. However, if the temperature of the sampling site is significantly different than the temperature that the device is calibrated with, the diffusion coefficient of a given analyte should be re-calculated, taking into consideration the dynamic viscosity of water at the alternate temperature.

\section{Kinetic calibration of open bed TF-SPME passive sampler}

Symmetry of desorption and absorption verification. To ensure the applicability of the method, the existence of isotropic behaviour of absorption between the analyteand device and desorption of the calibrantfrom the device should be verified. This experiment involved the simultaneous determination of thedesorption time profile of Ben-3- $\mathrm{d}_{5}$ as a calibrant, and the extraction time profile of Ben-3. Pre-loaded C18 thin film blades were exposed in the sampling 
chamber of theaqueous standard generator system for different sampling times in triplicate at agitation of $800 \mathrm{rpm}$, equal to linear velocity of $50 \mathrm{cmsec}^{-1}$, the linear velocity was calculated based on the agitation speed (revolution per minute), radius of the stir bar and distance of TFSPME from the center of the vessel. ${ }^{39}$ After each specified extraction time, the TF-SPMEwere removed from the sampling chamber and desorbed in the selected desorption solvent.The desorption process of the pre-loaded C18 thin film blades can be described by the following equation:

$\frac{Q}{q_{0}}=\exp \left(-a^{\prime} t\right)$

Where $\mathrm{q}_{0}$ is the amount of loaded calibrant on the extraction phase, $Q$ is the amount of calibrant remaining in the extraction phase after exposure to the sample matrix, $a^{\prime}$ is the desorption rate constantof the calibrant, and $t$ is sampling time. The kinetics of the absorption process for TF-SPME can be defined using the following equation:

$\frac{n}{n_{e}}=1-\exp (-a t)$

Where $\mathrm{n}$ is the amount of extracted analyte at sampling time $t, \mathrm{n}_{\mathrm{e}}$ is the amount of analyte extracted onto the coating at equilibrium, and a is the absorption rate constant of the analytes. The sums of $\mathrm{Q} / \mathrm{q}_{0}$ and $\mathrm{n} / \mathrm{ne}$ at any time were close to 1 , demonstrating the isotropy of the method.

$$
\frac{n}{n_{e}}+\frac{Q}{q_{0}}=1
$$


The linearized absorption and desorption time constant profiles can be obtained with $\ln (1-\mathrm{n} / \mathrm{ne})$ or $\ln \left(\mathrm{Q} / \mathrm{q}_{0}\right)$ as the $\mathrm{y}$-axis, where the regression slope is $-\mathrm{a}$. The rate constant $a$ is described by equation6:

(6) $a=\frac{D_{S} A}{V_{f} \delta_{S} K} a=\frac{D_{s} A}{V_{f} \delta_{S} K}$

Where $\mathrm{K}$ is the distribution coefficient of the analyte between the C18 coating and water, $A$ is the surface area, $V_{f}$ is the volume of the coating, $D_{s}$ is the diffusion coefficient of the analyte in water; and $\delta_{\mathrm{s}}$ is the thickness of the boundary layer. It is assumed that the diffusion boundary layer controlled kinetic. The thicknesses of the diffusion boundary layers are determined by hydrodynamics and the diffusivity of the analytes.For the sake of simplicity, thediffusive boundary which depends on diffusion coefficient was ignored because it is 10 times smaller than convective boundary layer. ${ }^{22}$

For desorption of calibrant, an equation similar to equation7 can be defined:

$a^{\prime}=\frac{D^{\prime}{ }_{s} A}{V_{f} \delta^{\prime}{ }_{S} K^{\prime}}$

Where $D^{\prime}{ }_{s}$ is the diffusion coefficient of the calibrant in water, and $K^{\prime}$ is the distribution coefficient of the calibrant between the C18 coating and water. Since the thickness of the diffusion layer, the surface area, and the volume of the coatingare the same for both target analytes $\left(\delta_{s}\right)$ and the calibrant $\left(\delta_{s}^{\prime}\right)$, the distribution coefficients of the analytes and calibrant between the C18 coating and water can be determined experimentally (see Supporting Information).Open bed TF-SPME coated withC18 (Figure 1b) was evaluated for monitoring of hydrophobic compounds with use of the one-calibrant kinetic calibration approach. The 
calibrantsolution was first loaded on the coating by performing an extraction from an aqueous solution containing $100 \mathrm{ng} \mathrm{mL}^{-1}$ of the calibrant in a $2 \mathrm{~mL}$ amber vial for $60 \mathrm{~min}$ at $1500 \mathrm{rpm}$ agitation. Then it was transferred to the sampling chamber of the aqueous standard generator system to investigate isotropismbetween absorption and desorption. The aqueous standard generator systemprovided a steady state free concentration of the analytes during the experiment. Extraction times ranged from 30-7230 min. Benzophenone-3 (Ben-3) andBenzophenone-3- $d_{5}\left(\right.$ Ben-3- $\left.d_{5}\right)$ were used as analyte and calibrant, respectively. Absorption rates related to the analytes under study were calculated with the use of equation 8 :

$\frac{a}{a^{\prime}}=\frac{D s K^{\prime}}{D^{\prime} s K}$

Equation 8 can be used to specify the relationships that exist between the desorption rate constant of the calibrant and the absorption rate constants of different compounds; accordingly, all extracted analytes can be quantified with a single pre-loaded calibrant. The distribution coefficient of Ben-3 was used for the calibrant Ben-3- $d_{5}$, as both compounds display the same retention time in the chromatographic separation on the $\mathrm{C} 18$ column, which indicates the similar physical-chemical properties between Ben-3- $d_{5}$ and Ben-3. In order to investigate the validity of equation 8for determination of TWA concentrations of other analytes, three C18 TF-SPME devices were loaded with the calibrant and exposed in the sampling chamber at50 $\mathrm{cmsec}^{-1}$ for $900 \mathrm{~min}$, where the uptake is still in the kinetic region of the extraction time profile, and the obtained concentrations can be assumed to be TWA concentrations. The concentration ofanalytes in the sample can be determinedusing equation9in the kinetic and equilibrium regime of the extraction time profile. 
$C_{S}=\frac{n}{K V_{f}[1-\exp (-a t)]}$

If the rate constants aand $a^{\prime}$ are the same, then equation 9 can be rewritten as the following equation:

$C_{S}=\frac{n}{K V_{f}\left[1-\exp \left(Q / q_{0}\right) t\right]}$

Where $C_{s}$ is the concentration of the analyte in the sample matrix.Based on equations 8,9 and 10,the open bed sampler can be deployed with a pre-loaded calibrant into the sample medium, retrieved after different sampling times, and then TWA concentration of the target analyte can be calculated.

Preparation of field samplers and on-site sampling procedures.On-site sampling was performed with a retracted sampler and an open bed device. Three disassembled retracted devices with a $10 \mathrm{~mm}$ diffusion path weretransported to the sampling location in appropriate containers to ensure that individual passive sampling devices remained isolated from the environment and each other during storage, transport to the deployment site, and return to the laboratory following retrieval. They were assembled under ultrapure water in the sampling location, and the opening of the device was covered by copper mesh in order to prevent biofouling from the sampling environment.On the other hand, three open bed C18TF-SPME devices (Figure S1a) were loaded with calibrant and wrapped with aluminum foil, then transported in a cold box filled with dry ice to the sampling location. Upon arrival, TF-SPME samplers were inserted individuallyinto copper bags (Figure S1b) to secure them in the 
sampling environment. All samplers were then placed in the plastic cage (Figure S1c) and deployed at the sampling site. Sampling time was 90 days for the retracted devices and 5 days for the open bed configuration. Once the sampling time had elapsed, the samplers were retrieved and rewrapped inaluminum foil,placed in the dry ice box, and transported to the laboratory.The analytes were desorbed in 1800 / $\mathrm{L}$ of a desorption solvent consisted of methanol/acetonitrile/isopropanol(50/25/25, v/v/v)for $30 \mathrm{~min}$. The desorption solvent was evaporated under nitrogen stream and residue was reconstituted in $300 / \mathrm{L}$ of methanol/water (50/50, v/v), then analyzed with the LC-MS/MS.

\section{RESULTS AND DISCUSSION}

Selection of the coating and TF-SPME passive samplers. The main objectiveof this study was to identify and evaluate TF-SPME approaches for the TWA determination of PCP compounds, which are comprised of a wide range of polarity. Preliminary evaluations revealed that relatively polar analytes, such as Ben-1, Ben-2, Ben-3, Ben-4 and PBSA, can be monitored by theretracted device sampler. In the retracted device, the coating is placed in a copper tube with a well-defined path length "boundary layer", in which the analytes diffuse through the narrow opening to the coating. According to coating selectionresults (Table S4 A-J), the HLB coating can be concluded to have a higher affinity for the polar compounds under study.However, for non-polar compounds, retracted devices may not provide reasonable TWA concentrations, as thesubstantial thermodynamic gradient drives the hydrophobic molecules out of the aqueous solution to stick to the wall of the diffusion path of the sampler. ${ }^{31}$ Thus, an 
open bed geometry, which can be easily calibrated with a kinetic calibration approach, was selected for extraction of thenon-polar compounds in thisstudy (OCR, OMC, TCC, TCS and BMDBM).The HLB coated TF-SPME was found to provideless desorption of the calibrant from the sampler to the solution (data not shown).However,the C18coatingnot only showed complete desorption of the calibrant from the sampler to solution, it also showed a better extraction efficiency than HLB for non-polar compounds. Therefore,C18 was selected for the open bed TFSPME device.The key characteristics of the two approaches are described in the following sections.

Retracted TF-SPME TWA sampler with HLB coating. The zero sinktest for the HLB coating was performed as described in the experimental section. A t-test was conducted to compare the results obtained for the different approaches, indicating that there was no statistically significant difference $(\langle=0.05)$ between amounts of extracted analytesfor intermittent and continuous exposure. Thus, it could be concluded that the HLB coating behaved as azero sinkfor all of the target analytes due to its strong affinity towards the analytes and the large capacity of the coating via surface adsorption. The amount of analytes adsorbed on the surface of the coating after 70 days of TWA sampling time corresponded to less than $5 \%$ of equilibrium amounts. The extraction time profiles of the analytes were investigated from 309660 min in triplicateusingHLB TF-SPME in sampling chamber of aqueous standard generator system in orderto find the equilibrium time and subsequently the extracted amount atequilibrium. The amounts of analytes extracted to the coating at equilibrium were 1200, 
$8000,1700,1350$, and 2200 ng for Ben-1, Ben-2, Ben-4, PBSA, and Ben-3, respectively. For the thin film retracted devicewith adiffusion path length of $10.0 \mathrm{~mm}$, the response time for the analytes was 4-10 $\mathrm{h}$. The response time is defined as the average dwelling time of an analyte inside the diffusion path, which can be easily calculated using equation 11 ,

Response time $=\frac{Z^{2}}{2 D}$

where $Z$ is the diffusion path length (in $\mathrm{cm}$ ) and $D$ isthe diffusion coefficient (in $\mathrm{cm}^{2} \mathrm{~s}^{-1}$ ). Nevertheless, response time is negligible in comparison to sampling time, which could be as long as 90 days. To confirm the third condition mentioned before, a face velocity effect test was carried out in a well-agitated sampling chamber $(800 \mathrm{rpm}$, calculated linear flow rate was $\sim 50$ $\left.\mathrm{cmsec}^{-1}\right)$ and in a mixing chamber where the linear velocity was low $\left(0.15 \mathrm{cmsec}^{-1}\right)$. Three samplers were exposed in each chamber for 30 days. The obtained results showed that there was no significant difference between accumulated masses in the samplersfor both conditions. This is a desired feature of the sampler for on-site applications, where convection conditionsaretypically variable and difficult to measure and calibrate for. 
Calibration ofretracted TF-SPMEpassive sampler.The diffusion coefficient of neutraland charged organic molecules in water can be obtainedusingequations S2 and S3. Table 1summarizes the experimental results for ( $\left.R_{s} Z\right) /(A D)$ at 5.0, 10.0, and $15.0 \mathrm{~mm}$ diffusion path lengths. The obtained results show that the values of (RsZ)/ (AD) for all analytes are close to 1. This indicates the zero sinkbehaviour of the HLB coating for the target analytes, thus confirming that diffusion calibration is the right calibration approach for this sampler.There areuncertainties associated with the measurement of the experimental and theoretical sampling rates, which are mainly dependent on fabrication of the device (A and L); determination of the diffusion coefficients in water; sampling time;and determination of amounts of extractedanalytesand concentrations of the analytes under study. As such, a $20 \%$ deviation from 1 was set as an acceptable value for TWA measurement in this study.

Table 1. Comparison of experimental values: $\left(R_{s} Z\right) /(A D)(n=3)$

\begin{tabular}{cccc}
\hline & \multicolumn{3}{c}{$\left(\mathbf{R s}_{\mathrm{s}} \mathrm{Z}\right) /(\mathrm{AD})$} \\
$\mathrm{B}$ & $\mathrm{Z}=0.5 \mathrm{~cm}$ & $\mathrm{Z}=1 \mathrm{~cm}$ & $\mathrm{Z}=1.5 \mathrm{~cm}$ \\
\cline { 2 - 4 } Ben 2 & $0.9 \pm 0.1$ & $0.9 \pm 0.1$ & $1.1 \pm 0.1$ \\
PBSA & $0.9 \pm 0.2$ & $0.9 \pm 0.2$ & $1.0 \pm 0.2$ \\
Ben 1 & $1.1 \pm 0.2$ & $1.0 \pm 0.2$ & $0.9 \pm 0.2$ \\
Ben3 & $0.9 \pm 0.1$ & $0.9 \pm 0.2$ & $0.9 \pm 0.2$ \\
& $1.0 \pm 0.2$ & $0.9 \pm 0.1$ & $1.0 \pm 0.2$ \\
\hline
\end{tabular}


Figure 2and FiguresS3-S6 demonstrate good correlations between the theoretical and experimental data for amount of analyteextracted, as well as good linear relationships between mass uptake and sampling times of up to 70 days. According to the trendsobserved for the amounts of analytes extracted, sampling time canpotentially be further extended, owing to the sufficiently large capacity of the thin film coating. The experimental results indicated that retracted TF-SPMEpassive sampling by HLB coating works very well for TWA sampling of polar compounds in water. Theretracted TF-SPME device was shown to meet all the required criteriafor successful performance as a TWA sampler,i.e. zerosink behaviour, response time, and independencefrom face velocity. The disadvantage of this sampler is itslow sampling rate and low response time in flashy conditions.It is important to note thatsampling time must be ensured to be sufficiently long to enable measurement of TWA concentrations in real environmental applications, as is the case for water monitoring.

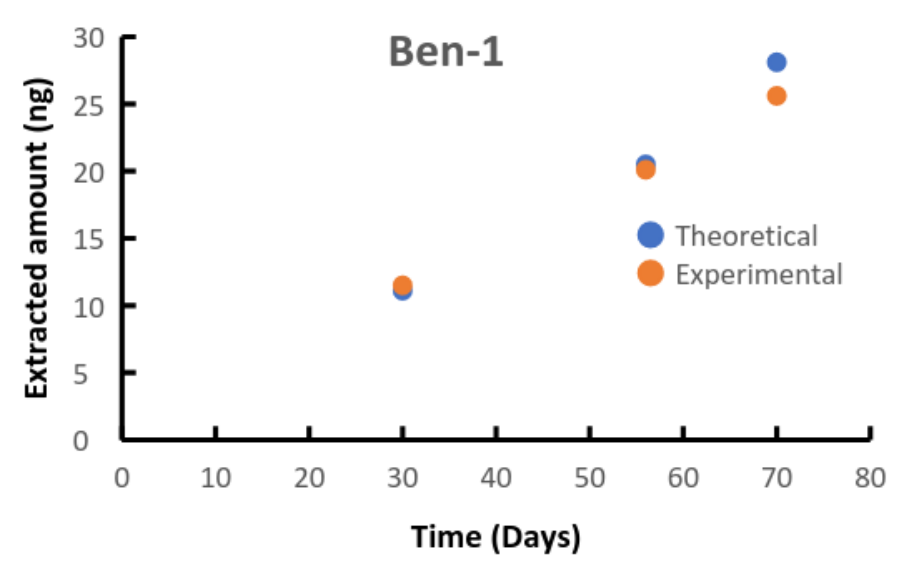


Figure 2. TWA concentration of Ben-1 using the retracted TF-SPME sampler (diffusion path: 10 $\mathrm{mm}$ and analyte concentration in the aqueous standard generator system: $138 \mathrm{ng} \mathrm{mL}^{-1}$ )

Open bed TF-SPMEpassive sampler with C18 coating.In the retracted device described in the previous section, the boundary layer thickness(diffusion path) is constant and not affected by convection conditions; therefore, calibration is straightforward and follows Fick's law. In the open bed configuration, since the sampler is directly exposed into the sampling location,the boundary layer is strongly dependent on the convection conditions; thus, acalibrant is necessary for adequatecalibration. The application of a kinetic calibration process was assessed using the aqueous standard generator system. This includedan evaluation of the symmetry of absorption and desorption of the analytes, as well as an investigation into the possibility of using a single calibrant for all tested compounds. The obtained data exhibited a good linear relationship between $\ln (1-n / n e)$ orln $\left(Q-q e / q_{0}\right)$, and time $(R>0.99)$, demonstrating that equations 3 and 4 accurately describe the kinetics of desorption and absorption (Figure 3). 

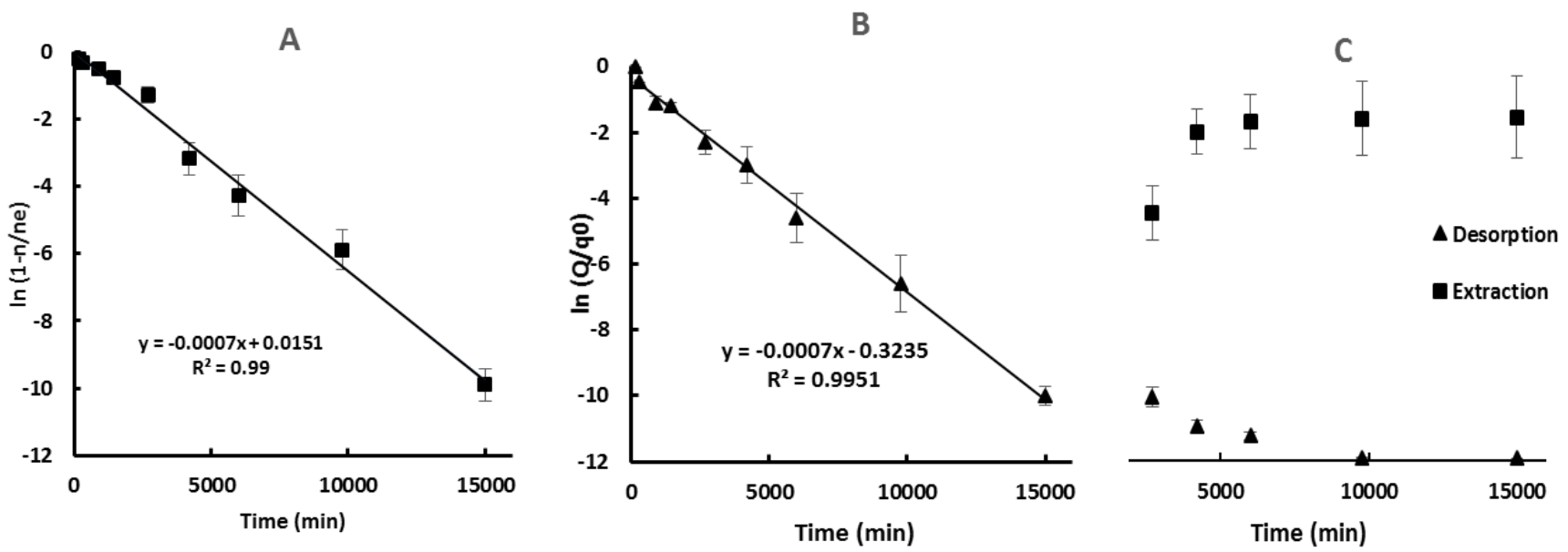

Figure 3. (A) Ben-3 absorption time profile (B) Ben-3- $d_{5}$ desorption time profiles(C) Isotropy of absorptionand desorption in TF-SPME

One-calibrant kinetic calibration of open bed TF-SPME passive sampler.Verification of theone calibrant kinetic calibration approach to estimate analyte absorption rate and subsequently calculate TWA concentrations of other hydrophobic analytes (OCR, OMC, BM-DBM, TCC, and TCS) was performed in theaqueous standard generator system. The quantitative results are shown in Table 2. It is clear that the one-calibrantkinetic calibration is able to quantify TWA concentrations of other analytes. It can be concluded from the $\mathrm{KV}_{\mathrm{f}}$ data (Table 2) that the used calibrant has the highest desorption or absorption rate in relation to the other analytes, which basically means that the sampling time could be longer than when the calibrant loss is $50 \%$. Although the temperature of the aqueous standard generator system $\left(24^{\circ} \mathrm{C}\right)$ is different from the temperature of the sampling site $\left(19-22^{\circ} \mathrm{C}\right)$ one-calibrant kinetic calibration is able to 
compensate for water temperatureand concentration changes in realistic sampling conditions. ${ }^{37}$ This is significant because temperature can affect the distribution and diffusion coefficients of the analytes which can be adjusted accordingly for average water temperatures during sampling time. The $\mathrm{pH}$ and ionic strength of the aqueous standard generator systemwas kept close to values characteristic ofthe sampling location so as to create a realistic sampling rate for the analytes. However, for compounds with a lower pKa, the average diffusion coefficient of ionic and neutral forms of a given molecule can be considered for laboratory calibration of the devices.

Table 2. Blade constant $\left(K V_{f}\right)$, diffusion coefficient $\left(D_{S}\right)$, absorption rate constant(a) and TWA concentrations of theanalytesin aqueous standard generator system (Mean \pm Standard Deviation; $\mathrm{n}=3$ )

\begin{tabular}{cccccc}
\hline Analytes & $\begin{array}{c}\mathbf{K V}_{\mathrm{f}}^{\mathrm{b}} \\
(\mathrm{mL})\end{array}$ & $\begin{array}{c}\left(\mathbf{D s} \times \mathbf{1 0} \mathbf{0}^{-5}\right)^{\mathrm{a}} \\
\left(\mathrm{cm}^{2} \mathrm{~s}^{-1}\right)\end{array}$ & $\begin{array}{c}\mathbf{a} \times \mathbf{1 0} \mathbf{0}^{\mathbf{4 b}} \\
\left(\mathrm{min}^{-1}\right)\end{array}$ & $\begin{array}{c}\text { Cone-calibrant } \\
\left(\mathrm{ngmL}^{-1}\right)\end{array}$ & $\begin{array}{c}\mathrm{C}_{\text {ASG }} \\
\left(\mathrm{ngmL}^{-1}\right)\end{array}$ \\
\hline OCR & 300 & 0.408 & $0.43 \pm 0.04$ & $0.25 \pm 0.03$ & $0.24 \pm 0.04$ \\
OMC & 80 & 0.458 & $2.8 \pm 0.1$ & $0.08 \pm 0.01$ & $0.08 \pm 0.01$ \\
BM-DBM & 400 & 0.460 & $0.24 \pm 0.03$ & $0.12 \pm 0.02$ & $0.12 \pm 0.01$ \\
TCS & 180 & 0.358 & $1.3 \pm 0.1$ & $3.2 \pm 0.4$ & $3.3 \pm 0.3$ \\
TCC & 220 & 0.536 & $2.8 \pm 0.3$ & $1.2 \pm 0.2$ & $1.3 \pm 0.1$ \\
Ben-3-d5 & 30 & 0.508 & $6.6 \pm 0.5$ & $28 \pm 3$ & $28 \pm 2$ \\
\hline
\end{tabular}
a: Calculated
b: Determined 
On-site water sampling with TWA samplers. The two TWA samplers developed and validated in the laboratory were subsequently usedforan on-site investigation. The downstream of the Doon (Kitchener) municipal wastewater treatment plant, whichreaches Grand River(Southern Ontario, Canada) $\left(43^{\circ} 28^{\prime} 23.21^{\prime \prime} \mathrm{N}\right.$; $\left.80^{\circ} 28^{\prime} 40.4^{\prime \prime} \mathrm{W}\right)$, wasselected for deployment of the devices (Figure S8) as the indirect input of this contamination stems from effluent of a wastewater treatment plant. Sampling time of the retracted device was selected in view of typical concentration levels found for the analytes in pre-screened investigations as well as the detection limit of the LC-MS/MS instrument. Two samplers were deployed at the same time and the samplingtime for retracted and open TF-SPME TWA samplers was set as 90 and 5 days, respectively.Average concentrations and relative standard deviations (RSD) of spot sampling and TWA sampling results are shownin Table 3.The TWA concentrations of the analytes were calculated with the use of equation 1.The results obtained by the two methods are similar.Ben1, Ben-3, Ben-4, and PBSA were detected in spot sampling,whileonly PBSA and Ben-4 were detected in TWA sampling. This isdue to the low sampling rate of the device, and the low concentrations of Ben-1 and Ben-3 in river water. ${ }^{38}$ No biofouling of the phase was observed for HLB TF-SPME,substantiating previous reports by other researchers in the literature. ${ }^{40-42}$ The stability of the analytes on the extraction phase was validatedin laboratory by two months exposure of analyte pre-loaded thin films to collected river water and compared to analyte preloaded control thin films which were immersed in purewater with $\mathrm{pH}$ and ionic strength adjustedto reflect typical river water. All experiments were performed in triplicate, and the results of the two studies were compared by t-test. No statistical differences observed $(\alpha=0.05)$ 
between the two sets of data which agrees with previous studies where it was reported that the analytes are more stable in theextraction phase rather than in the sample matrix. ${ }^{43,44}$ Three of the open bed samplers were retrieved after 2, 5, and 10 days. Analysis showed that $50 \%$ of the calibrant was lost within 5 days of sampling, which was determined to be the optimum time for measuring TWA concentrations. TCS, OCR, and Ben-3 were detected and quantified byequation10, withresults shownin Table 3 . In addition to TWA sampling with open bed TFSPME, spot sampling, conducted by grab sampling with a bottle, was investigated for determination of the concentrations of analytes over the TWA sampling time (see SI for grab sampling procedure). Although the used sampler has the lowest limits of detection for OMC,TCC and BM-DBM, these compoundswere not detected in the sampling site (see SI for limits of detection of TWA samplers, grab samplings and instrument (Table S5)). In addition to the potential effects of biodegradation ${ }^{45}$ and photodegradation, ${ }^{46}$ the lack of detection of these analytes may be explained by their high binding coefficient to sediment, as they possess ahigh distribution coefficient between water anddissolved organic carbon (DOC) or particulates, caused by their high Kow value. Yet another reason would beeffective elimination of these compounds in wastewater treatment plants. Both formats of TF-SPME presented in this research can measure the free concentrations of analytesin complex matrices when DOC or particulates are present. Binding to organic carbon lowers the free fraction of organic contaminantsthe sampling uptake of highly bound analytes. Moreover, procedural and field blank samples were analyzed, and none of the analytes under study were detected (see SI for blank sample procedure). The data in Table 3 shows good agreement between the TWA passive 
sampling methods and relevant spot sampling results. The targeted analytes were also reported by other researchers in different sampling sitesknown to hold comparable concentrationsto thosedetected in Grand River, as reported in this research.

Additionally, possible biofouling on the sampling devices was also investigated. As previously mentioned, the samplers were protected in copper mesh bags in order to prevent biofouling. In addition, the retracted devices that were deployed for a longer time were further protected from biofouling by being retracted in the sampler. Moreover, polyacrylonitrile, which was used to immobilize HLB and C18 particles, serves as a biocompatible glue and membrane, providing additional protection from biofouling. Thus, in none of the deployed devices was biofouling observed.A scanning electron microscopy (SEM) image, shown in Figure S9, reveals that the devices were free from any biofouling after on-sitedeployment.

The field study showed that the one-calibrant kinetic calibration is perfectly suitable for quantitation of hydrophobic compounds in river waters. The concentrations that were found by the developed passive samplers are consistent with typical concentrations reported in the literature. ${ }^{47-53}$ However, this comparison is qualitative in nature; the matrix of the sampling location, sampling season, usage pattern of personal care products, and the type of sewage treatments being implemented at individual plants may all contribute to apparent concentrations.

This study demonstrated the feasibility of practical deployment and TWA concentration measurement for two different passive sampling devices, namely, open bed TF-SPME and retracted TF-SPME. The combination of bothdeveloped methods offers an integrated approach 
for TWA determination of analytes with a wide range of physical-chemical properties for on-site applications. Retracted TF-SPME devices using the HLB coating offer a promising passive sampling method for monitoring of polar analytes in water, without the need for calibration or control of convection conditions. The implementation of such a sampler is straight-forward compared to other passive sampling methods such as the polar organic chemical integrative sampler (POCIS), since the use of such a samplerrequires calibration in the laboratory or field. The retracted TF-SPME sampler showedrelatively high detection limits for the target analytes which may limit the large-scale application of field sampling in less-impacted regions. However, in certain cases, the detection limits of the sampler can be improved by decreasing the diffusion path and increasing the diameter of the opening.Application of the open bed configuration using the one-calibrant method with C18 coating showed its capability for measurement of the TWA concentrations of hydrophobic compounds in instances where their isotopic labelled standards are either not available or affordable. The limitation of the evaluated sampler is its dependency on the convection conditions, which effects the desorption rate of the calibrant, thus limiting its use for long-term monitoring only at low convection conditions. In addition, determination of the $\mathrm{K}$ value was necessary in this approach, although this step is only required to be performed once for a given sampler and given target analyte. Such a method could be potentially applied to TWA measurement of other non-polar environmental chemicals by using different calibrants to cover a wider range of compounds and/or a thicker coating, which would proportionally increase the capacity of the sampler, thus allowing longer sampling times before unacceptable depletion of the calibrant. 
Table 3. Field sampling results of retracted TF-SPME and open bed TF-SPME TWA samplers in Grand River, ON

\begin{tabular}{|c|c|c|c|c|c|c|}
\hline \multirow[b]{2}{*}{$\begin{array}{l}\text { Grab sampling with open } \\
\text { bed HLB TF-SPME } \\
\text { (Equilibriumsampling) }\end{array}$} & \multicolumn{6}{|c|}{ Concentration $\left(\mathrm{ngL}^{-1}\right)$} \\
\hline & $\begin{array}{c}\text { Ben-1 } \\
\text { (RSD, \%) }\end{array}$ & $\begin{array}{c}\text { Ben-3 } \\
\text { (RSD, \%) }\end{array}$ & $\begin{array}{c}\text { Ben-4 } \\
\text { (RSD, \%) }\end{array}$ & $\begin{array}{c}\text { PBSA } \\
\text { (RSD, \%) }\end{array}$ & $\begin{array}{c}\text { Ben- } 2 \\
\text { (RSD, \%) }\end{array}$ & \\
\hline Jun 13- Jun $22(n=3)$ & $5(7)$ & $23(12)$ & $4500(12)$ & $2300(20)$ & $<0.5$ & \\
\hline Jul15 - Jul 24 (n=3) & $5(13)$ & $17(11)$ & $6000(11)$ & $4000(12)$ & $<0.5$ & \\
\hline Aug 12- Aug 21 ( $n=3)$ & $6(8)$ & $19(6)$ & $6600(15)$ & $4900(11)$ & $<0.5$ & \\
\hline Average & 5 & 20 & 5700 & 3700 & $<0.5$ & \\
\hline \multicolumn{7}{|l|}{ Retracted HLB TF- } \\
\hline SPMETWA Sampler $(n=3)$ & $<700$ & $<800$ & $5400(15)$ & $4000(12)$ & $<130$ & \\
\hline \multicolumn{7}{|l|}{ Jun 13- Sep 13} \\
\hline Procedural blank & $<500$ & $<1000$ & $<2500$ & $<500$ & $<100$ & \\
\hline Field blank & $<700$ & $<800$ & $<160$ & $<130$ & $<500$ & \\
\hline Cross reference data & $12^{49}$ & $32.7^{54}$ & $1481^{47}$ & $2503^{47}$ & $32^{55}$ & \\
\hline \multirow{2}{*}{$\begin{array}{l}\text { One-calibrant kinetic } \\
\text { calibration }\end{array}$} & \multicolumn{6}{|c|}{ Concentration $\left(\mathrm{ngL}^{-1}\right)$} \\
\hline & $\begin{array}{c}\mathrm{OCR} \\
(\mathrm{RSD}, \%)\end{array}$ & $\begin{array}{c}\text { TCS } \\
\text { (RSD, \%) }\end{array}$ & $\begin{array}{l}\text { Ben-3 } \\
\text { (RSD, \%) }\end{array}$ & $\begin{array}{c}\mathrm{OMC} \\
\text { (RSD, \%) }\end{array}$ & $\begin{array}{c}\text { TCC } \\
\text { (RSD, \%) }\end{array}$ & $\begin{array}{l}\text { BM-DBM } \\
\text { (RSD, \%) }\end{array}$ \\
\hline \multicolumn{7}{|l|}{ Open bed C18 TF-SPME } \\
\hline $\begin{array}{l}\text { TWAsampler ( } n=3 \text { ) } \\
\text { Jun 13- Jun } 17\end{array}$ & $90(9)$ & $36(5)$ & $27(19)$ & $<0.04$ & $<0.01$ & $<0.01$ \\
\hline $\begin{array}{l}\text { Grab sampling ( } n=6) \\
\text { Jun } 13, \text { Jun } 17\end{array}$ & $130(15)$ & $50(15)$ & $28(10)$ & $<20$ & $<0.1$ & $<3$ \\
\hline Procedural blank & $<1000$ & $<100$ & $<1000$ & $<500$ & $<1$ & $<160$ \\
\hline Field blank & $<0.2$ & $<0.2$ & $<0.5$ & $<0.04$ & $<0.1$ & $<0.01$ \\
\hline Cross reference data & $23^{56}$ & $18^{56}$ & $20^{57}$ & $33^{58}$ & $3.5^{49}$ & $68^{50}$ \\
\hline
\end{tabular}




\section{ASSOCIATED CONTENT}

Supporting Information: Additional information, as noted in the text, includes details related to analytical methods, chemicals, LC-MS/MS parameters, experimental procedure, TFSPME optimization, preparation of samplers, evaluation and deployment,detection limits of TWA samplers, and grab samplers.

\section{AUTHOR INFORMATION}

\section{Corresponding Author}

*E-mail address: janusz@uwaterloo.ca

Tel.: +1-519-888-4641; Fax: +1-519-746-0435

\section{ACKNOWLEDGEMENTS}

The authors would like to acknowledge Unilever (project number: 057423)and the Natural Sciences and Engineering Research Council of Canada(project number: 050165) for financial support and Mr. Jonathan J. Grandy for his help with on-site sampling. 


\section{REFERENCES}

(1) Liu, H.; Liu, L.; Xiong, Y.; Yang, X.; Luan, T. Simultaneous determination of UV filters and polycyclic musks in aqueous samples by solid-phase microextraction and gas chromatography-mass spectrometry. J. Chromatogr. A2010, 1217 (43), 6747-6753.

(2) Richardson, S.; Ternes, T. A. Water Analysis: Emerging Contaminants and Current Issues. Anal. Chem.2014, 81 (12), 4645-4677.

(3) Vrana, B.; Allan, I. J.; Greenwood, R.; Mills, G. A.; Dominiak, E.; Svensson, K.; Knutsson, J.; Morrison, G. Passive sampling techniques for monitoring pollutants in water. TrAC Trends Anal. Chem.2005, 24 (10), 845-868.

(4) Aguilar-Martínez, R.; Palacios-Corvillo, M. A; Greenwood, R.; Mills, G. A; Vrana, B.; Gómez-Gómez, M. M. Calibration and use of the Chemcatcher passive sampler for monitoring organotin compounds in water. Anal. Chim. Acta2008, 618 (2), 157-167.

(5) Thomatou, A. A.; Zacharias, I.; Hela, D.; Konstantinou, I. Passive sampling of selected pesticides in aquatic environment using polar organic chemical integrative samplers. Environ. Sci. Pollut. Res.2011, 18, 1222-1233.

(6) Alvarez, D. A; Stackelberg, P. E.; Petty, J. D.; Huckins, J. N.; Furlong, E. T.; Zaugg, S. D.; Meyer, M. T. Comparison of a novel passive sampler to standard water-column sampling for organic contaminants associated with wastewater effluents entering a New Jersey stream. Chemosphere2005, 61 (5), 610-622.

(7) Cristale, J.; Katsoyiannis, A.; Chen, C.; Jones, K. C.; Lacorte, S. Assessment of flame retardants in river water using a ceramic dosimeter passive sampler. Environ.

Pollut.2013, 172, 163-169.

(8) Petty, J. D.; Orazio, C. E.; Huckins, J. N.; Gale, R. W.; Lebo, J. A; Meadows, J. C.; Echols, K. R.; Cranor, W. L. Considerations involved with the use of semipermeable membrane devices for monitoring environmental contaminants. J. Chromatogr. A2000, 879 (1), 8395.

(9) Seethapathy, S.; Górecki, T.; Li, X. Passive sampling in environmental analysis. J. 
Chromatogr. A2008, 1184 (1-2), 234-253.

(10) Gourlay-Francé, C.; Lorgeoux, C.; Tusseau-Vuillemin, M.-H. Polycyclic aromatic hydrocarbon sampling in wastewaters using semipermeable membrane devices: accuracy of time-weighted average concentration estimations of truly dissolved compounds. Chemosphere2008, 73 (8), 1194-1200.

(11) Chelan, L.; Ellis, S. G.; Booij, K.; Kaputa, M. Chemosphere Comparison of semipermeable membrane device ( SPMD ) and large-volume solid-phase extraction techniques to measure water concentrations of 4,40 -DDT ,. 2006, 72 (2008), 1112-1117.

(12) Harman, C.; Allan, I. J.; Vermeirssen, E. L. M. Calibration and use of the polar organic chemical integrative sampler--a critical review. Environ. Toxicol. Chem.2012, 31 (12), 2724-2738.

(13) Bayen, S.; Segovia, E.; Loh, L. L.; Burger, D. F.; Eikaas, H. S.; Kelly, B. C. Application of Polar Organic Chemical Integrative Sampler (POCIS) to monitor emerging contaminants in tropical waters. Sci. Total Environ.2014, 482-483, 15-22.

(14) Vermeirssen, E. L. M.; Dietschweiler, C.; Escher, B. I.; Voet,V. D., J.; Hollender, J. Uptake and release kinetics of 22 polar organic chemicals in the Chemcatcher passive sampler. Anal. Bioanal. Chem.2013, 405 (15), 5225-5236.

(15) Bopp, S.; Weiss, H.; Schirmer, K. Time-integrated monitoring of polycyclic aromatic hydrocarbons (PAHs) in groundwater using the Ceramic Dosimeter passive sampling device. J. Chromatogr. A2005, 1072, 137-147.

(16) Allan, I. J.; Harman, C.; Kringstad, A.; Bratsberg, E. Effect of sampler material on the uptake of PAHs into passive sampling devices. Chemosphere2010, 79 (4), 470-475.

(17) Allan, I. J.; Harman, C.; Ranneklev, S. B.; Thomas, K. V; Grung, M. Passive sampling for target and nontarget analyses of moderately polar and nonpolar substances in water. Environ. Toxicol. Chem.2013, 32 (8), 1718-1726.

(18) Booij, K.; Robinson, C. D.; Burgess, R. M.; Mayer, P.; Roberts, C. A.; Ahrens, L.; Allan, I. J.; Brant, J.; Jones, L.; Kraus, U. R.; Larsen, M. M.; Lepom, P.; Petersen, J.; Pröfrock, D.; Roose, P.;Schäfer, S.;Smedes, F.; Tixier, C.;Vorkamp, K.; and Whitehouset P.;. Passive Sampling in Regulatory Chemical Monitoring of Nonpolar Organic Compounds in the Aquatic Environment. Environ. Sci. Technol.2016, 50 (1), 3-17.

(19) Fernandez, L. A.; Harvey, C. F.; Gschwend, P. M. Using performance reference compounds in polyethylene passive samplers to deduce sediment porewater concentrations for numerous target chemicals. Environ. Sci. Technol.2009, 43 (23), 88888894.

(20) Jacquet, R.; Miège, C.; Smedes, F.; Tixier, C.; Tronczynski, J.; Togola, A.; Berho, C.; Valor, I.; Llorca, J.; Barillon, B.;P. Coquery,M. M.; Comparison of five integrative samplers in laboratory for the monitoring of indicator and dioxin-like polychlorinated biphenyls in 
water. Chemosphere2014, 98 (2014), 18-27.

(21) Allan, I. J.; Booij, K.; Paschke, A.; Vrana, B.; Mills, G. A.; Greenwood, R. Field performance of seven passive sampling devices for monitoring of hydrophobic substances. Environ.

Sci. Technol.2009, 43 (14), 5383-5390.

(22) Lohmann, R.; Muir, D. C. G.; Zeng, E. Y.; Bao, L.-J.; Allan, I. J.; Arinaitwe, K.; Booij, K.; Helm, P. A.; Kaserzon, S. L.; Mueller, J. F.;Mueller,Shibata,Y.;Smedes, F.;Tsapakis M.;Wong C. S.; and YouJ.;Aquatic Global Passive Sampling (AQUA-GAPS) Revisited - First Steps towards a Network of Networks for Organic Contaminants in the Aquatic Environment. Environ. Sci. Technol.2017, 51, 1060-1067

(23) Arthur, C.; Pawlyszin, J. Solid phase microextraction with thermal desorption using fused silica optical fibers. Anal. Chem.1990, 62 (19), 2145-2148.

(24) Ouyang, G.; Pawliszyn, J. A critical review in calibration methods for solid-phase microextraction. Anal. Chim. Acta2008, 627 (2), 184-197.

(25) Duan, C.; Shen, Z.; Wu, D.; Guan, Y. Recent developments in solid-phase microextraction for on-site sampling and sample preparation. TrAC Trends Anal. Chem.2011, 30 (10), 1568-1574.

(26) Martos, P. A; Pawliszyn, J. Time-weighted average sampling with solid-phase microextraction device: implications for enhanced personal exposure monitoring to airborne pollutants. Anal. Chem.1999, 71 (8), 1513-1520.

(27) Chen, Y.; Pawliszyn, J. Solid-phase microextraction field sampler. Anal. Chem.2004, 76 (22), 6823-6828.

(28) Ouyang, G.; Zhao, W.; Bragg, L.; Qin, Z.; Alaee, M.; Pawliszyn, J. Time-weighted average water sampling in Lake Ontario with solid-phase microextraction passive samplers. Environ. Sci. Technol.2007, 41 (11), 4026-4031.

(29) Ouyang, G.; Zhao, W.; Alaee, M.; Pawliszyn, J. Time-weighted average water sampling with a diffusion-based solid-phase microextraction device. J. Chromatogr. A2007, 1138 (1-2), 42-46.

(30) Ouyang, G.; Chen, Y.; Pawliszyn, J. Time-weighted average water sampling with a solidphase microextraction device. Anal. Chem.2005, 77 (22), 7319-7325.

(31) Chen, Y.; Pawliszyn, J. Time-weighted average passive sampling with a solid-phase microextraction device. Anal. Chem.2003, 75 (9), 2004-2010.

(32) Boyaci, E.; Gorynski, K.; Rodriguez-Lafuente, A.; Bojko, B.; Pawliszyn, J. Introduction of solid-phase microextraction as a high-throughput sample preparation tool in laboratory analysis of prohibited substances. Anal. Chim. Acta2014, 809, 69-81.

(33) Mirnaghi, F. S.; Chen, Y.; Sidisky, L. M.; Pawliszyn, J. Optimization of the coating procedure for a high-throughput 96 -blade solid phase microextraction system coupled 
with LC-MS/MS for analysis of complex samples. Anal. Chem.2011, 83 (15), 6018-6025.

(34) Ooij, K. E. E. S. B.; Leiderink, H. E. M. S.; Medes, F. O. S. Calibrating the uptake kinetics of semipermeable membrane devices using exposure standards. 1998, 17 (7), 1236-1245.

(35) Huckins, J. N.; Petty, J. D.; Lebo, J. A; Almeida, F. V; Booij, K.; Alvarez, D. a; Cranor, W. L.; Clark, R. C.; Mogensen, B. B. Development of the permeability/performance reference compound approach for in situ calibration of semipermeable membrane devices.

Environ. Sci. Technol.2002, 36 (1), 85-91.

(36) Bragg, L.; Qin, Z.; Alaee, M.; Pawliszyn, J. Field sampling with a polydimethylsiloxane thinfilm. J. Chromatogr. Sci.2006, 44 (6), 317-323.

(37) Ouyang, G.; Cui, S.; Qin, Z.; Pawliszyn, J. One-calibrant kinetic calibration for on-site water sampling with solid-phase microextraction. Anal. Chem.2009, 81 (14), 5629-5636.

(38) Ouyang, G.; Chen, Y.; Pawliszyn, J. Time-Weighted Average Water Sampling with a SolidPhase Microextraction Device. 2010, 77 (22), 7319-7325.

(39) Pawliszyn, J. Handbook of Solid Phase Microextraction; Elsevier, 2012.

(40) Risticevic, S.; Niri, V. H.; Vuckovic, D.; Pawliszyn, J. Recent developments in solid-phase microextraction. Anal. Bioanal. Chem.2009, 393 (3), 781-795.

(41) Mazzella, N.; Lissalde, S.; Moreira, S.; Delmas, F.; Mazellier, P.; Huckins, J. N. Evaluation of the use of performance reference compounds in an Oasis-HLB adsorbent based passive sampler for improving water concentration estimates of polar herbicides in freshwater. Environ. Sci. Technol.2010, 44 (5), 1713-1719.

(42) Reyes-Garcés, N.; Bojko, B.; Hein, D.; Pawliszyn, J. Solid Phase Microextraction Devices Prepared on Plastic Support as Potential Single-Use Samplers for Bioanalytical Applications. Anal. Chem.2015, 87 (19), 9722-9730.

(43) Pawliszyn, J. Why move analysis from laboratory to on-site? TrAC Trends Anal. Chem.2006, 25 (7), 633-634.

(44) Bojko, B.; Cudjoe, E.; Gómez-Ríos, G. A; Gorynski, K.; Jiang, R.; Reyes-Garcés, N.; Risticevic, S.; Silva, É. A. S.; Togunde, O.; Vuckovic, D.; et al. SPME-quo vadis? Anal. Chim. Acta2012, 750, 132-151.

(45) Zenker, A.; Schmutz, H.; Fent, K. Simultaneous trace determination of nine organic UVabsorbing compounds (UV filters) in environmental samples. J. Chromatogr. A2008, 1202 (1), 64-74.

(46) MacManus-Spencer, L. A; Tse, M. L.; Klein, J. L.; Kracunas, A. E. Aqueous photolysis of the organic ultraviolet filter chemical octyl methoxycinnamate. Environ. Sci. Technol.2011, 45 (9), 3931-3937.

(47) Rodil, R.; Quintana, J. B.; López-Mahía, P.; Muniategui-Lorenzo, S.; Prada-Rodríguez, D. 
Multiclass determination of sunscreen chemicals in water samples by liquid chromatography-tandem mass spectrometry. Anal. Chem.2008, 80 (4), 1307-1315.

(48) Rodil, R.; Moeder, M. Development of a method for the determination of UV filters in water samples using stir bar sorptive extraction and thermal desorption-gas chromatography-mass spectrometry. J. Chromatogr. A2008, 1179 (2), 81-88.

(49) Wick, A.; Fink, G.; Ternes, T. A. Comparison of electrospray ionization and atmospheric pressure chemical ionization for multi-residue analysis of biocides, UV-filters and benzothiazoles in aqueous matrices and activated sludge by liquid chromatographytandem mass spectrometry. J. Chromatogr. A2010, 1217 (14), 2088-2103.

(50) Bratkovics, S.; Sapozhnikova, Y. Determination of seven commonly used organic UV filters in fresh and saline waters by liquid chromatography-tandem mass spectrometry. Anal. Methods2011, 3 (12), 2943.

(51) Wu, J.L.; Lam, N. P.; Martens, D.; Kettrup, A.; Cai, Z. Triclosan determination in water related to wastewater treatment. Talanta2007, 72 (5), 1650-1654.

(52) Cheng, C. Y.; Wang, Y. C.; Ding, W.H. Determination of triclosan in aqueous samples using solid-phase extraction followed by on-line derivatization gas chromatography-mass spectrometry. Anal. Sci.2011, 27 (2), 197-202.

(53) Hua, W.; Bennett, E. R.; Letcher, R. J. Triclosan in waste and surface waters from the upper Detroit River by liquid chromatography-electrospray-tandem quadrupole mass spectrometry. Environ. Int.2005, 31 (5), 621-630.

(54) Liu, Y. S.; Ying, G. G.; Shareef, A.; Kookana, R. S. Simultaneous determination of benzotriazoles and ultraviolet filters in ground water, effluent and biosolid samples using gas chromatography-tandem mass spectrometry. J. Chromatogr. A2011, 1218 (31), 5328-5335.

(55) Kasprzyk-Hordern, B.; Dinsdale, R. M.; Guwy, A. J. Multiresidue methods for the analysis of pharmaceuticals, personal care products and illicit drugs in surface water and wastewater by solid-phase extraction and ultra performance liquid chromatographyelectrospray tandem mass spectrometry. Anal. Bioanal. Chem.2008, 391 (4), 1293-1308.

(56) Cuderman, P.; Heath, E. Determination of UV filters and antimicrobial agents in environmental water samples. Anal. Bioanal. Chem.2007, 387 (4), 1343-1350.

(57) Balmer, M. E.; Buser, H.-R.; Müller, M. D.; Poiger, T. Occurrence of some organic UV filters in wastewater, in surface waters, and in fish from Swiss Lakes. Environ. Sci. Technol.2005, 39 (4), 953-962.

(58) Li, W.; Ma, Y.; Guo, C.; Hu, W.; Liu, K.; Wang, Y.; Zhu, T. Occurrence and behavior of four of the most used sunscreen UV filters in a wastewater reclamation plant. Water Res.2007, 41 (15), 3506-3512. 
